Document downloaded from:

http://hdl.handle.net/10251/162243

This paper must be cited as:

Tampau, A.; González Martínez, MC.; Chiralt Boix, MA. (2020). Biodegradability and disintegration of multilayer starch films with electrospun PCL fibres encapsulating carvacrol. Polymer Degradation and Stability. 173:1-8. https://doi.org/10.1016/j.polymdegradstab.2020.109100

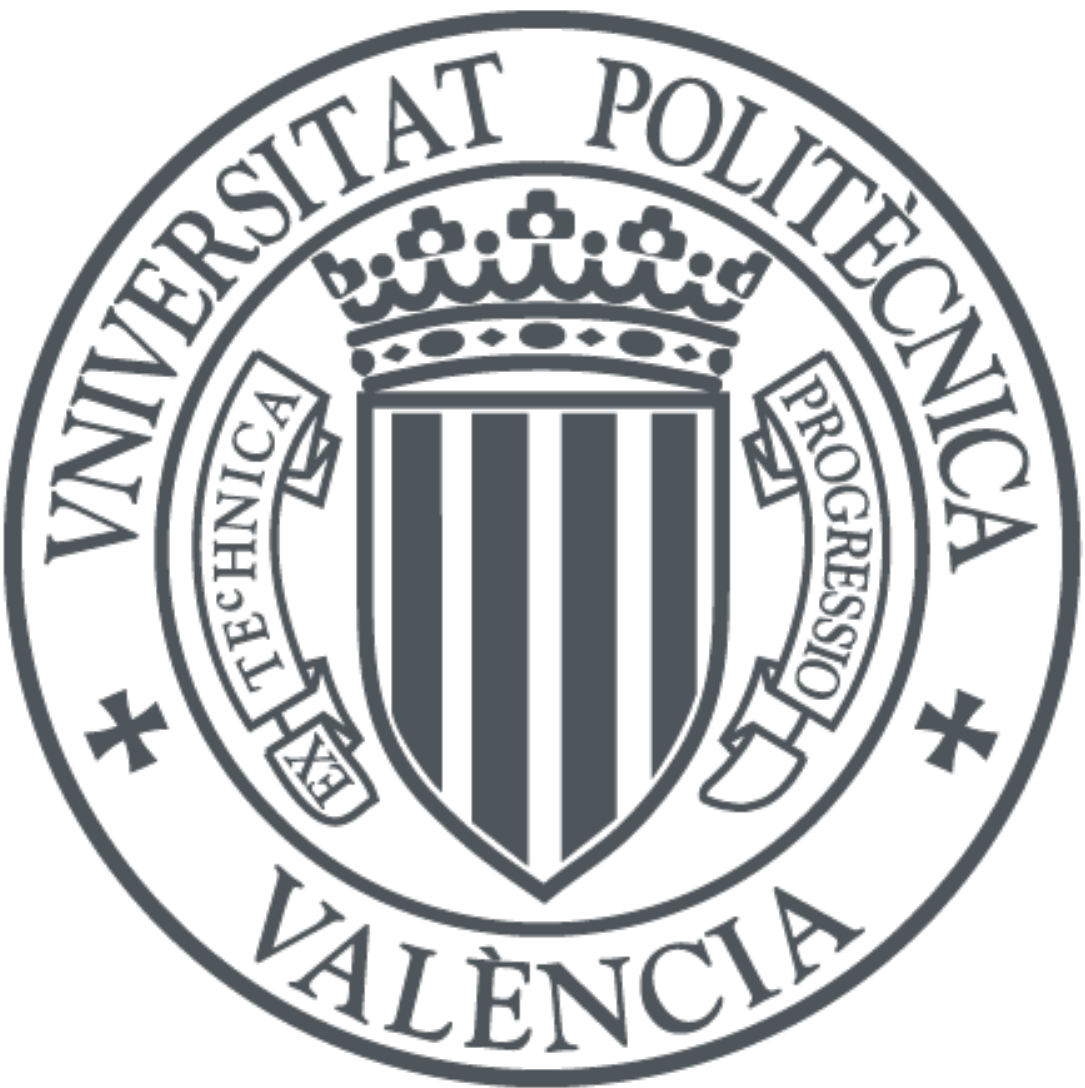

The final publication is available at

https://doi.org/10.1016/j.polymdegradstab.2020.109100

Copyright Elsevier

Additional Information 


\title{
Biodegradability and disintegration of multilayer starch films with electrospun PCL fibres encapsulating carvacrol
}

\author{
Alina Tampau ${ }^{1 a}$, Chelo González-Martínez ${ }^{2 b}$, Amparo Chiralt ${ }^{3 c}$ \\ a, b, c Instituto Universitario de Ingeniería de Alimentos para el Desarrollo, Ciudad Politécnica de la Innovación, \\ Universitat Politécnica de Valencia, Camino de Vera, s/n, 46022 Valencia, Spain. \\ ${ }^{1}$ altam@upv.es, ${ }^{2}$ cgonza@ tal.upv.es, ${ }^{3}$ dchiralt@ @tal.upv.es
}

1 Abstract

2 The biodegradation and disintegration of thermoplastic starch multilayers containing carvacrol(CA)3 loaded poly-( $\varepsilon$-caprolactone) electrospun mats were evaluated under thermophilic composting 4 conditions for 45 and 84 days, respectively, and compared with non-loaded carvacrol films and pure 5 starch films. Sample mass loss, thermogravimetric and visual analyses were performed throughout 6 the disintegration test. The disintegration behaviour of all multilayers was similar, reaching values 7 of $75-80 \%$ after 84 days. Biodegradation, assessed by carbon dioxide measurements, revealed 8 that all the carvacrol-free films completely biodegraded after 25 composting days. However, the 9 presence of CA notably affected the compost inoculum activity, thus limiting the biodegradability of 10 the CA-loaded multilayers to a maximum value of around $85 \%$ after 45 days. Nevertheless, this 11 value was close to that established by the standard ISO method to qualify as biodegradable 12 material.

13 Keywords: thermoplastic starch; poly-( $\varepsilon$-caprolactone); carvacrol; TGA; disintegration; 14 biodegradation.

Abbreviations: EFSA, European Food Safety Authority; S, starch; PCL, poly-(e-caprolactone); CA, carvacrol; GAA, glacial acetic acid; MCC, microcrystalline cellulose; TGA, thermogravimetric analysis; DTGA, derivative thermogravimetric analysis; SSR, synthetic solid residue; DS, dry solids; VS, volatile solids; MC, moisture content;

\section{Introduction}

21 The quantity of plastics produced in the first 10 years of the current century is likely to approach the quantity produced in the entire preceding century [1] and only a modest percentage of these

\footnotetext{
${ }^{1}$ Corresponding autor details:

Mailing address: Instituto Universitario de Ingeniería de Alimentos para el Desarrollo, Ciudad Politécnica de la Innovación, building 8E Access F, L0-03, Universitat Politécnica de Valencia, Camino de Vera, s/n, 46022 Valencia, Spain.

E-mail address: altam@upv.es
} 
packaging materials ends up being recycled (plastic recycling rates of 9.1\% in the US in 2015 [2] and $40.9 \%$ in the EU in 2016 [3]). The usage and disposal of plastics is controversial and there are growing concerns about waste accumulation, problems for wildlife resulting from ingestion and the potential for plastics to transfer harmful chemicals to wildlife and humans. There are numerous studies alerting to the alarming levels of microplastics found in oysters [4], mussels [5],[6],[7] crabs [8] and fish [9], [10] which move up through the food chain, ending up in the human body. Risk assessments developed by the European Food Safety Authority (EFSA) [11] have taken these considerations into account. However, perhaps the most important overriding concern is that our current usage is not sustainable [1].

Due to the environmental impact these plastics generate owing to their long degradation times, more effort is being made to develop packaging from biodegradable materials. This trend is aligned with consumer demand for more natural products for food contact materials. As a result, new materials have been developed, using biodegradable polymers from renewable sources, such as polysaccharides and proteins, and natural active agents of plant or marine origin.

Starch $(S)$ is one of the most commonly studied, readily available carbohydrates, obtainable from renewable sources at relatively low cost. Starch films present very good oxygen barrier capacity, but due to their hydrophilic nature, films exhibit water sensitivity and poor water vapour barrier properties. Combining, in multilayer assemblies, starch layers with sheets of hydrophobic polymers - with high water vapour barrier capacity - would provide these materials, intended for food packaging, with more adequate barrier capacity for both water vapour and oxygen. In this sense, poly-( $\varepsilon$-caprolactone) (PCL) (a completely biodegradable aliphatic polyester) [12] has been combined with thermoplastic corn starch, forming bilayers with improved barrier properties when compared to neat starch films [13], [14]. These multilayer films became active films with antimicrobial properties by incorporating carvacrol encapsulated into electrospun PCL layers [14]. The encapsulation of carvacrol in PCL mats by electrospinning showed better retention of the compound in this non-polar matrix, exhibiting higher encapsulation efficiency than starch [15]. Likewise, electrospinning is applied at room temperature which also contributes to preserve the compound against the potential deterioration and volatilization that can occur during the starch thermal processing. Carvacrol (CA) is a phenolic monoterpene, one of the major constituents of oregano and thyme essential oils [16]. It exhibits significant in vitro antimicrobial [17], [18], [19] and antioxidant activity [20], [21], and has been approved as a food additive by Joint FAOMHO [22] and as flavouring substance by EFSA [23]. It is currently being used as a bioactive in packaging materials [24], [25], [26]. Thus, the addition of active compounds to biopolymer layers confers antimicrobial and/or antioxidant properties, making these materials more attractive as food packaging candidates. Given the inhibiting effect of such antimicrobial compounds on microflora, it is likely that the biodegradation of these matrices could be altered by the presence of active compounds [27], [28]. 
60 Composting is a form of organic recycling, based on the activity of the microbiota population, which 61 breaks down the biodegradable parts of the waste, generating stabilized organic residue [29]. The resulting compost could be used as soil conditioner to increase soil productivity by replenishing some of its nutrients, and reduce the excessive use of synthetic fertilizers [27]. As pointed out by Balaguer et al. [27], not all biodegradable polymers are compostable, since compostability implies biodegradation by biological processes at a rate consistent with other known compostable materials, leaving non-visibly distinguishable or toxic residues. Therefore, evaluation of compostability includes three phases: disintegration, biodegradation and ecotoxicity. The biodegradability and compostability of developed active packaging materials made with biodegradable polymers can be affected by the presence of actives or blend interactions and cannot be assumed as such. It must be analysed to ensure that the newly created materials comply with the requirements specified by law [29].

The aim of this study is to assess the disintegration and biodegradation behaviour under laboratory composting conditions of starch-PCL multilayer films, incorporating or not carvacrol.

\section{Materials and experimental design}

\subsection{Materials}

Starch for film preparation was provided by Roquette Laisa España S.A. (Benifaió, Valencia, Spain), while PCL pellets (average $M_{n} 80,000$ ), $C A$ and glacial acetic acid (GAA) were obtained from SigmaAldrich (Sigma-Aldrich Chemie, Steinheim, Germany).

For the biodegradation and disintegration studies, ripe compost (no older than 4 months) was offered by a local solid residue treatment plant (Valencia, Spain). Other components used for the disintegration test consisted of urea (Urea 46\% Prill, Tarazona, Spain), sawdust (Productos de Limpieza Adrian, Almacera, Valencia,Spain), corn starch (Roquette Laisa España S.A. (Benifaió, Valencia, Spain), rabbit-feed (Super Feed S.L., Madrid, Spain), saccharose (White sugar, Azucarera Ebro, Madrid, Spain) and corn seed oil (Hacendado brand, Mercadona supermarkets, Spain). For the biodegradation test, vermiculite from a local market was used. Microcrystalline cellulose (MCC) (powder, $20 \mu \mathrm{m}$ ) was purchased from Sigma Aldrich Química S.L., Madrid, Spain. Magnesium nitrate $\left(\mathrm{Mg}\left(\mathrm{NO}_{3}\right)_{2}\right)$ and Phosphorous pentoxide $\left(\mathrm{P}_{2} \mathrm{O}_{5}\right)$ used for creating controlled relative humidity environments for sample storage were purchased from Panreac Química S.A. (Castellar de Valles, Barcelona, Spain).

91

\subsection{Films preparation}

93 The starch films were prepared by compression moulding, following the protocol described previously by Tampau et al. [14]. Briefly, a mixture of starch : glycerol : water=1 : $0.3: 0.5$ (wt. / wt.) was processed in a two-roll mill (Model LRM-M-100, Labtech Engineering, Thailand) at $160{ }^{\circ} \mathrm{C}$ and 
with saturated $\mathrm{Mg}\left(\mathrm{NO}_{3}\right)_{2}$ aqueous solution, to ensure a $53 \%$ relative humidity. Each individual starch film was obtained from 4 grams of conditioned pellet, moulded by thermo-compression in a press (Model LP20, Labtech Engineering, Thailand), at 50 bars / $160{ }^{\circ} \mathrm{C}$ for 2 min, then at 130 bars / $160 \stackrel{\circ}{\circ} \mathrm{C}$ for $6 \mathrm{~min}$ and cooled down to $50^{\circ} \mathrm{C}$ for $3 \mathrm{~min}$.

Multilayer films were prepared by coating one side of a starch film with an electrospun layer (application time of 90 minutes, voltage $15.0 \mathrm{kV}$, flow-rate $1.2 \mathrm{~mL} / \mathrm{h}$, distance needle-collector 15 $\mathrm{cm}$ ) of a PCL solution (15 \% wt. / wt.) in GAA with or without CA (15 g carvacrol / $100 \mathrm{~g} \mathrm{PCL}$ ), following the methodology described by Tampau et al. [14], using a Fluidnatek Biolnicia (Valencia, Spain) equipment. Later on, the PCL-coated starch films were thermo-compressed with another neat starch film at 130 bars / $80^{\circ} \mathrm{C}$ for $4 \mathrm{~min}$ followed by a cooling at $50{ }^{\circ} \mathrm{C}$ for 2 min. Thus, three multilayer films were obtained: starch-starch (SS), starch-PCL-starch (SPS) and starch-PCL-starch containing carvacrol in the PCL layer (SPCAS). Thermocompression under the described conditions gave rise to a good layer adhesion in normal conditions, although these layers partially detached when starch sheets swelled under high moisture conditions, in which these films would not be applicable.

\subsection{Samples characterization}

\section{2.3.1. Moisture content, elemental composition and visual appearance}

115 Prior to the tests, the multilayer films were analysed as to their moisture content (as described by 116 Cano et al. [28]) and thickness, measured in 5 different points using a Palmer digital micrometre 117 (Comecta, Barcelona, Spain). In order to determine the $\mathrm{C}, \mathrm{N}$ and $\mathrm{H}$ composition of the samples, an 118 elemental analysis was performed by means of a Euro EA3000 analyser (EUROVECTOR, Milan, 119 Italy). Analyses were carried out in triplicate.

120 The visual changes that samples presented throughout the disintegration experiments were 121 analysed. For this purpose, specific samples extracted from the reactors at different times were previously dried in a vacuum oven at $40^{\circ} \mathrm{C}$ for a week. Pictures were taken by means of a digital camera (EOS 5D Mark II, Canon, Japan).

\subsubsection{Thermogravimetric analysis}

The samples were submitted to a thermogravimetric analysis (TGA) at different times of the composting process (day 0,14, 21, 42 and 84). Prior to this analysis, the composted samples were conditioned by drying in a vacuum oven at $40{ }^{\circ} \mathrm{C}$ for one week and later transferred to a desiccator with $\mathrm{P}_{2} \mathrm{O}_{5}$ until constant weight. A TGA/SDTA 851e analyser (Mettler Toledo, Schwarzenbach, Switzerland) working under nitrogen flow $(20 \mathrm{~mL} / \mathrm{min}$ ) was used to obtain the weight loss curves vs. temperature (TGA) and the first derivatives (DTGA). Between 5 and $10 \mathrm{mg}$ of conditioned sample was placed in a $70 \mu \mathrm{L}$ alumina crucible and heated from 25 to $600{ }^{\circ} \mathrm{C}$ at $10 \mathrm{~K} / \mathrm{min}$. With the software provided by the Mettler Toledo analyser, the onset, peak and end temperatures of the degradation steps were obtained. All measurements were done in triplicate. 
134 2.4. Compost and synthetic solid residue (SSR)

135 The ripe compost (acting as the inoculum) was prepared by removing any inert pieces like shards 136 of glass and stones, and then sieved. Its $\mathrm{pH}$ was assessed by mixing 1 part compost to 5 parts 137 deionized water and measured immediately, to ensure a value between 7 and 9 .

138 Following the ISO 20200 International Standard (2004) [30], a synthetic solid residue (SSR) was 139 prepared for the disintegration test, by manually mixing the required components described in 140 section 2.1. For the purpose of the biodegradation test, the inoculum was just mixed with vermiculite 141 to prevent compacting and thus ensuring good oxygenation. For both tests, the water content was 142 adjusted to $55 \%$ (wt. / wt.) by adding de-ionized water and gently stirring. This ensured the compost 143 was moist, but without visible free water.

144 The SSR was characterized as to its dry solids (DS) and volatile solids (VS) content, as specified 145 by ISO 20200 [30], both at the beginning, as well as at the end of the composting process (84 days). 146 The DS was determined by drying the analysed sample in an oven at $105^{\circ} \mathrm{C}$ until constant mass 147 was reached and expressed as a percentage of the total mass of the analysed sample. The VS was 148 obtained from the previously dried sample by calcination at $550^{\circ} \mathrm{C}$ in a muffle (Selecta, Barcelona, 149 Spain) until constant weight, and expressed as a percentage with respect to the DS. The ripe 150 compost used for the biodegradation study was also characterized in terms of DS and VS at initial 151 time.

\section{2.5. Disintegration test}

153 Disintegration test was carried out in the laboratory, following the International Standard guidelines 154 [30]. Roughly 10 grams of film samples (cut into $25 \times 25 \mathrm{~mm}$ squares) were placed with $1 \mathrm{~kg}$ of wet 155 SSR in each composting unit (reactor) consisting of a polypropylene box with lid. On each one of 156 the narrow sides of the reactor, one hole (5 mm in diameter) was made at approximately $6.5 \mathrm{~cm}$ 157 from the bottom, to allow gas exchange between the inside and outside atmospheres. The filled 158 reactors were placed in an oven (Selecta, J.P. Selecta S.A., Barcelona, Spain) at $58 \pm 2 \stackrel{\circ}{ } \mathrm{C}$ to ensure 159 controlled thermophilic conditions. Their initial weight was recorded and was closely monitored 160 throughout the duration of the essay (84 days), restoring it totally or partially with de-ionised water, 161 as specified by the aforementioned ISO standard [30]. Three reactors per formulation were 162 prepared, each reactor containing less than $10 \mathrm{~g}$ total mass of samples included in mesh bags $(1 \mathrm{x}$ $1631 \mathrm{~mm}$ mesh size). One of these samples with around $5 \mathrm{~g}$ (cut into $25 \times 25 \mathrm{~mm}$ squares) was used 164 to control the sample weight loss at the final time, according to the standard guidelines, and the 165 other mesh bags, each with only one sample square $(25 \times 25 \mathrm{~mm}$, about $0.3 \mathrm{~g})$ were extracted from 166 the reactor at different control times in order to carry out the TGA and visual analysis (described in 167 168 169 section 2.3), and the weight control. Prior to these analyses, the mesh bags containing samples were gently cleaned with a soft brush to eliminate the adhered compost residues. The disintegration percentage after 84 days $\left(D_{84}(\%)\right)$ was calculated by means of the eq. 1 : 
171 where $m_{0}$ is sample dry mass at the start of test and $m_{84}$ is dry mass of the final disintegrated

172 samples after 84 composting days.

173

174

175

\subsection{Biodegradation test}

The starch films containing electrospun PCL material were also submitted to an aerobic biodegradation assessment under controlled composting conditions following the guidelines of the ISO 14855-1 standard method [31], as adapted by other authors [27] and [28] by mixing the nonactivated vermiculite and compost to prevent the compost compaction and ensure good oxygen access. The principle of this method assumes that the $\mathrm{CO}_{2}$ that forms during the biodegradation of a sample is directly proportional to the carbon percentage that is biodegraded from that respective sample. The test was performed inside airtight glass jars of $2000 \mathrm{~mL}$ in volume, whose lids were modified with a covered septum. Inside the jars, 2 polypropylene cups were placed: one containing $3 \mathrm{~g}$ of dry compost mixed with $1 \mathrm{~g}$ of vermiculite and a sample quantity (previously cut in $2 \mathrm{~mm}^{2}$ squares) equivalent to $50 \mathrm{mg}$ of carbon, while the second one, contained water to ensure $100 \%$ relative humidity inside the jar. The samples were maintained up to 45 days at $58 \pm 2{ }^{\circ} \mathrm{C}$. A control sample was also prepared using MCC as reference material [27]. A blank sample contained just compost with vermiculite. The percentage of $\mathrm{CO}_{2}$ generated inside the reactors was measured in triplicate using a $\mathrm{CO}_{2}$ analyser (CheckMate 9900 PBI Dansensor, Ringsted, Denmark) throughout the biodegradation process.

The theoretical amount of $\mathrm{CO}_{2}$ that could be generated from the sample ( $\left.\mathrm{CO}_{2}^{T h}{ }_{S}\right)$ was estimated from its carbon content applying eq. 2. The biodegradation percentage $(B \%)$ at each time was calculated as the ratio between the cumulative amounts of $\mathrm{CO}_{2}$ produced by the sample throughout the 45 days with respect to the theoretical amount $\left(\mathrm{CO}_{2}^{T h}{ }_{S}\right)$, applying eq. 3 [31].

$$
\begin{gathered}
C O_{2}^{T h}{ }_{S}=D W_{S} \cdot C_{S} \cdot \frac{M w_{C O_{2}}}{M w_{C}} \\
B \%=\frac{\sum C O_{2 S}-\sum C O_{2 B}}{C O_{2}^{T h}{ }_{S}}
\end{gathered}
$$

where:

$-D W_{S}$ is the dry weight of sample $(g)$;

- $\mathrm{C}_{\mathrm{s}}$ is the percentage of carbon in the dry sample, as determined by elemental analysis (\%);

- $\mathrm{Mw}_{\mathrm{CO}_{2}}$ and $M w_{C}$ are the molecular weights of $\mathrm{CO}_{2}$ and of $\mathrm{C}$ respectively;

$-\sum \mathrm{CO}_{2 S}$ is the cumulative amount of carbon dioxide in the sample reactors at each time throughout test period $(\mathrm{g})$;

$-\sum \mathrm{CO}_{2 B}$ is the cumulative amount of carbon dioxide detected in the blank reactor at each time $(\mathrm{g})$.

The experimental data obtained from the biodegradation test was modelled using Hill's equation (eq.4) in order to describe the kinetics of the process. 
207 Where:

$208-\mathrm{B} \% \max$ is the percentage of biodegradation at infinite time (\%);

$209-\mathrm{t}$ is the time (days);

$210-\mathrm{k}$ is the time at which $0.5 \mathrm{~B} \% \max$ has occurred;

$211-n$ is the curve radius of the sigmoid function.

\section{$212 \quad$ 2.7. Statistical analysis}

213 All statistical analysis were performed through analysis of variance (ANOVA) using the application 214 STATGRAPHICS Centurion XVI (Statgraphics Technologies, Inc., The Plains, Virginia 20198, USA). Fisher's lest significant difference (LSD) procedure was used at the 95\% confidence level.

\section{Results}

\subsection{Properties of multilayer films}

Table 1 presents the properties of the starch film samples prior to the tests. As can be observed, while the films presented similar moisture content values among formulations, the presence of the electrospun layer of PCL significantly increased the film thickness and the carbon content of these multilayers, according to the presence of PCL with higher $\mathrm{C}$ ratio in the molecule. The thickness of multilayer films notably increased with respect to the usual thickness of monolayer films. [32].

Table 1. Samples' moisture content (MC), thickness and elemental carbon (C \%) analysis prior to the composting test. Mean values and standard deviation.

\begin{tabular}{|c|c|c|c|}
\hline Sample / reactor & MC (\%) & Thickness $(\mu \mathrm{m})$ & $\mathbf{C} \%$ \\
\hline SS & $6.73 \pm 0.16^{\mathrm{ab}}$ & $430 \pm 30^{\mathrm{a}}$ & $40.4 \pm 0.2^{\mathrm{a}}$ \\
\hline SPS & $6.59 \pm 0.16^{\mathrm{a}}$ & $500 \pm 30^{\mathrm{b}}$ & $41.2 \pm 0.6^{\mathrm{ab}}$ \\
\hline SPCAS & $6.956 \pm 0.010^{\mathrm{b}}$ & $490 \pm 20^{\mathrm{b}}$ & $42.3 \pm 1.3^{\mathrm{b}}$ \\
\hline
\end{tabular}

\subsection{Compost characteristics}

229 The active compost used as inoculum for both tests presented a pH of 8.25 (measured according 230 to the ISO method), total dry solids (DS) content of $70 \pm 1 \%$ and organic matter content of $56 \pm 1 \%$ 231 (expressed as volatile solids (VS) with respect to the dry solids). Characteristics of the pre232 composting SSR prepared for the disintegration test are shown in Table 2. The volatile solids 233 content decreased slightly at the end of the composting process with respect to the initial value, as 234 an indicator of the organic matter being converted into $\mathrm{CO}_{2}$ by the compost microflora. Then, the test was validated taking into account the standard method, which established a reduction of the 
236 volatile content in the sample after the composting period ( $\mathrm{R}$ values, Table 2 ) of over $30 \%$ as well 237 as the standard deviation of the disintegration values of the samples $\left(D_{84}(\%)\right.$, in Table 2$)$ lower than 23810 units. Likewise, throughout the duration of the test, the colour changes described by the ISO 23920200 standard [30] were observed in the compost (from lighter yellow (due to sawdust presence) 240 to a darker brown). The odour of the compost was strongly ammoniacal within the first week, and it 241 disappeared gradually, according to that described in ISO 20200 standard [30].

243 Table 2. Volatile solids VS (g volatiles / $100 \mathrm{~g}$ compost DS) before and after the composting period 244 of the disintegration test, the difference between these values (R: expressed as \% with respect to 245 the initial value) and disintegration percentage for the samples. Mean values and standard 246 deviations.

\begin{tabular}{|c|c|c|c|c|}
\hline \multirow{2}{*}{ Reactor } & \multicolumn{2}{|c|}{$\begin{array}{c}\text { VS } \\
(\mathrm{g} / 100 \mathrm{~g} \mathrm{DS})\end{array}$} & $\begin{array}{c}R \\
(\%)\end{array}$ & \multirow{2}{*}{$\begin{array}{c}\text { Disintegration } \\
D_{84}(\%)\end{array}$} \\
\hline & $\begin{array}{c}\text { Pre } \\
\text { composting }\end{array}$ & $\begin{array}{c}\text { Post } \\
\text { composting }\end{array}$ & $\begin{array}{c}\text { Decrease in } \\
\text { VS }\end{array}$ & \\
\hline SSR (blank) & \multirow{4}{*}{$95.0 \pm 0.3$} & $91.3 \pm 0.6^{c}$ & $43 \pm 1^{a}$ & - \\
\hline SS & & $80.5 \pm 0.7^{a}$ & $55 \pm 1^{b}$ & $75 \pm 6^{a}$ \\
\hline SPS & & $85.9 \pm 1.1^{b}$ & $52 \pm 2^{b}$ & $81.1 \pm 0.5^{a}$ \\
\hline SPCAS & & $84.5 \pm 0.5^{b}$ & $51 \pm 2^{b}$ & $75 \pm 4^{a}$ \\
\hline
\end{tabular}

Different superscript letters $(a, b, c \ldots)$ in the same column indicate significant differences $(p<0.05)$ among samples.

\section{3.3. Disintegration test}

249 The degree of disintegration (D) of films when exposed to laboratory-scale composting 250 environmental conditions ( $58 \pm 2{ }^{\circ} \mathrm{C}$ for 84 days) provided information about the physical breakdown 251 of films into smaller fractions. Figure 1 shows the disintegration values as a function of time for the 252 different samples. As shown, all films presented similar disintegration patterns taking into account 253 the uncertainty associated with the sample mass control. It is difficult to ensure the lack of compost 254 particles in the sample and the complete delivery of the disintegrated sample particles from the 255 mesh, since under moist environment these remain stuck/agglomerated and compacted under the 256 mechanical action of the mesh. Similar asymptotic values were attained for the different samples 257 (75-80 \%) after about 14 days, although the final values shown in Table 2 correspond to the samples 258 introduced in the reactor for the purpose of this control, according to standard guidelines, at the end 259 of the test period (84 days). The mass fluctuations throughout the asymptotic period can be 260 attributed to the different amounts of adhered compost particles or to different losses of disintegrated sample particles through the mesh. The visual appearance of the samples at different composting times is also presented in Figure 2. It is remarkable that about 14 days only were required to disintegrate the films as can be deduced from both Figures 1 and 2 . In fact, the visual appearance of the samples at 14 days corresponded to agglomerated particles with certain degree 

of the mesh.

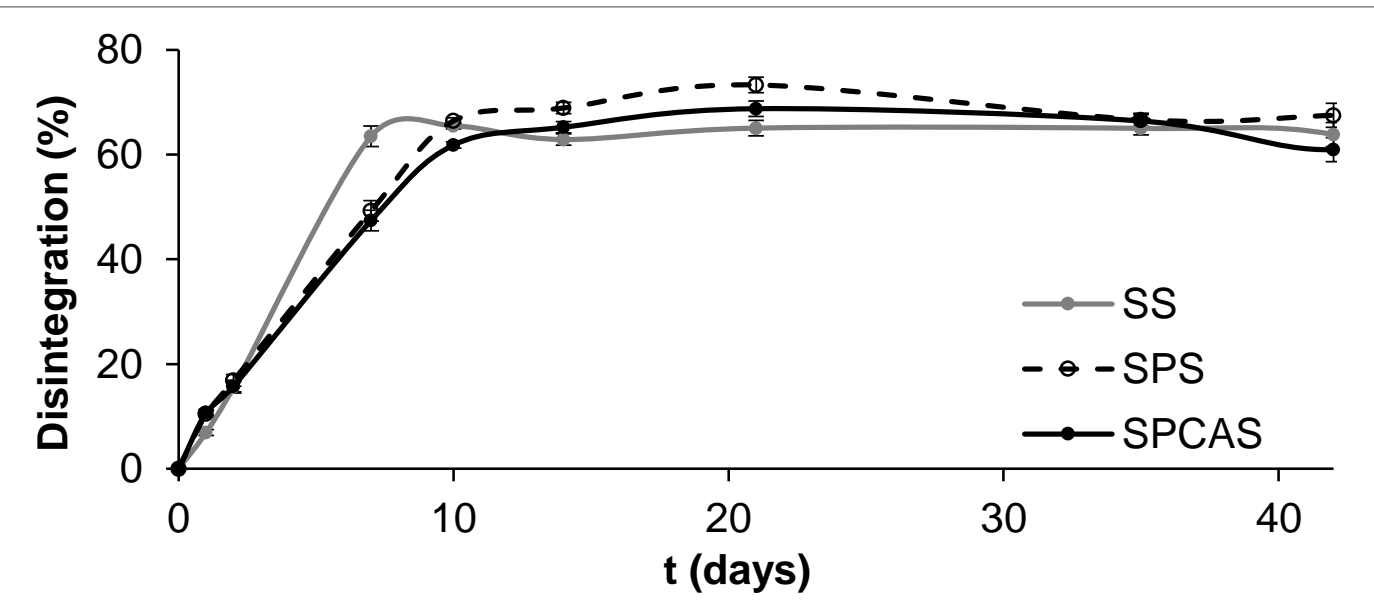

Figure 1. Development of sample disintegration as a function of time for the different multilayer 270 films. (Mean values and LSD intervals $(p<0.05)$ ).

271 Non-significant differences $(p<0.05)$ in the $D_{84}(\%)$ values were found among samples at the end of 272 the composting period, being the mean $D_{84}(\%)$ value $77 \pm 5 \%$. These values are in agreement with 273 those mentioned by Castro-Aguirre et al. [33] for trays with similar composition. As reported by 274 Balaguer et al. [27], the erosion kinetics are affected by two major factors: 1) the water diffusion 275 through the polymer layer and 2) the rate of degradation of the polymeric chains. Other authors [28] 276 observed higher disintegration rates for starch films obtained by casting which could be attributed 277 to differences in the films thickness and polymer arrangements in the film structure obtained by 278 different processing methods. Nevertheless, this disintegration process in the obtained bilayer films 279 was very similar according to their similar specific surface. This permits the water diffusion and 280 uptake, favouring the microbial action and bulk erosion, thus breaking the matrix in small fragments.

\begin{tabular}{|c|c|c|c|}
\cline { 2 - 4 } \multicolumn{1}{c|}{} & \multicolumn{3}{c|}{ Sample } \\
\hline day & SS & SPS & \\
\hline & & & \\
& & & \\
& & & \\
\hline 1 & & & \\
\hline & & & \\
\hline & & & \\
\hline
\end{tabular}




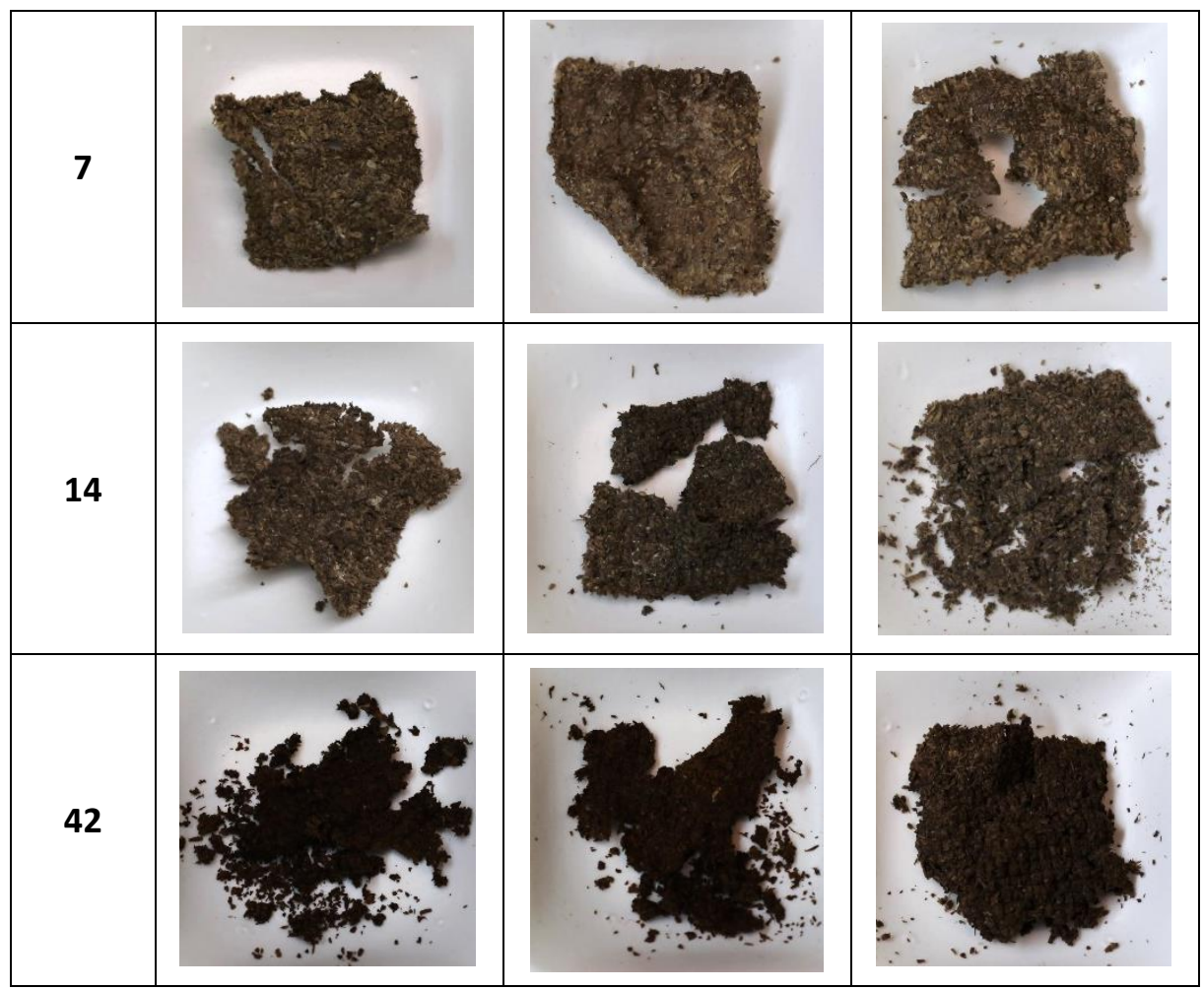

281 Figure 2. Visual appearance of the samples throughout the disintegration period.

282 The degradation degree of polymer throughout the disintegration period has been analysed via 283 thermogravimetric analysis at different times. Figure 3 shows TGA and DTGA curves obtained for 284 the films at different times and Table 3 gives the onset and peak temperatures for the degradation 285 steps of the samples at initial and final time of the disintegration test. As can be observed in Figure 2863 , samples presented a first degradation step at around 61-63 ${ }^{\circ} \mathrm{C}\left(T_{\mathrm{p}}\right)$, corresponding to the 287 evaporation of bound water. This step was not detected in the samples at initial time $(t=0)$, which 288 suggests that the partially degraded samples exhibit greater water binding capacity due to the 289 changes in the mean molecular weight or composition of the substrate. The main peak 290 corresponding to the starch degradation showed the maximum degradation rate at $T_{p}$ around 280$291290 \stackrel{\circ}{\circ}$, in agreement with the value reported by Collazo-Bigliardi et al. [34] for starch films. 292 However, it is remarkable that the peak became wider and split throughout the composting period. 293 This reflects the formation of starch subunits of lower molecular weight that degrade at lower 294 temperature, as has been observed by other authors [35], [36]. The mass loss profiles (DTGA 295 curves) slightly vary for the different multilayers. This suggests differences in the degradation 296 mechanisms in each case, depending on the presence of PCL and carvacrol. The degradation step 297 of electrospun PCL at about $360^{\circ} \mathrm{C}$ (as described by Tampau et al. [14]) only appeared in the initial 298 samples, and it was no longer observed in samples at 14 days of the process. This suggests most 299 of the PCL polymer chains were quickly broken down by the composting bacteria due to the low 300 thickness (less than $60 \mu \mathrm{m}$ ) of the electrospun layer and the possible detachment of the multilayer 
301 assembly, promoted by the starch swelling in the wet compost environment, which increases the 302 specific surface area of the PCL sheet and the disintegration's effectiveness. There was no thermo303 released carvacrol detected for the samples submitted to TGA analysis at different times of the 304 disintegration process. This can be due to its low mass fraction in the bilayer (about 0.5 ), as reported 305 in a previous study [14].

306 The percentage of residual mass at $600^{\circ} \mathrm{C}$ is also presented in Table 3. All initial samples showed 307 low values for this parameter, which significantly $(p<0.05)$ increased after the composting period. 308 The increase in the residual mass after 84 days can be fully justified by disappearance of the organic 309 fraction of the sample (forming $\mathrm{CO}_{2}, \mathrm{~N}_{2}, \mathrm{CH}_{4}$, and $\mathrm{H}_{2} \mathrm{O}$ ) during biodegradation, with the subsequent 310 increase of mass fraction of mineral content, as observed by other authors [28]. However, sample 311 contamination with compost particles could also contribute to the increase in the residue.

312 Table 3. TGA parameters obtained for the pre- and post- composting samples: onset $\left(T_{0}\right)$, peak $313\left(T_{p}\right)$, endset $\left(T_{e}\right)$ temperatures, and pyrolysis residual mass at $600 \stackrel{\circ}{ } \mathrm{C}$. Different superscript letters 314 in the same column indicate significant differences $(p<0.05)$ among samples.

\begin{tabular}{|c|c|c|c|c|c|c|c|c|c|}
\hline \multirow{2}{*}{ Sample } & \multirow{2}{*}{ Day } & \multicolumn{3}{|c|}{$1^{\text {st }}$ step } & \multicolumn{2}{c|}{$2^{\text {nd }}$ step } & \multicolumn{2}{c|}{$3^{\text {rd }}$ step } & Residual \\
\cline { 3 - 9 } & & $T_{0}$ & $T_{p}$ & $T_{e}$ & $T_{0}$ & $T_{p}$ & $T_{o}$ & $T_{p}$ & mass (\%) \\
\hline \multirow{2}{*}{ SS } & 0 & - & - & - & $257 \pm 1^{b}$ & $286 \pm 2^{b}$ & - & - & $3 \pm 3^{a}$ \\
\cline { 2 - 10 } & 84 & $37 \pm 4^{\mathrm{a}}$ & $63 \pm 1^{\mathrm{a}}$ & $109 \pm 3^{\mathrm{a}}$ & $223 \pm 11^{\mathrm{a}}$ & $290 \pm 1^{\mathrm{c}}$ & - & - & $34 \pm 5^{\mathrm{b}}$ \\
\hline \multirow{2}{*}{ SPS } & 0 & - & - & - & $244 \pm 2^{\mathrm{b}}$ & $281 \pm 1^{\mathrm{a}}$ & $331 \pm 15^{\mathrm{a}}$ & $366 \pm 5^{\mathrm{a}}$ & $6 \pm 1^{\mathrm{a}}$ \\
\cline { 2 - 10 } & 84 & $39 \pm 4^{\mathrm{a}}$ & $62 \pm 3^{\mathrm{a}}$ & $104 \pm 4^{\mathrm{a}}$ & $227 \pm 15^{\mathrm{a}}$ & $293 \pm 2^{\mathrm{d}}$ & - & - & $37 \pm 4^{\mathrm{b}}$ \\
\hline \multirow{2}{*}{ SPCAS } & 0 & - & - & - & $244 \pm 1^{\mathrm{b}}$ & $282 \pm 1^{\mathrm{a}}$ & $321 \pm 28^{\mathrm{a}}$ & $362 \pm 8^{\mathrm{a}}$ & $5 \pm 2^{\mathrm{a}}$ \\
\cline { 2 - 10 } & 84 & $37 \pm 4^{\mathrm{a}}$ & $61 \pm 4^{\mathrm{a}}$ & $105 \pm 3^{\mathrm{a}}$ & $243 \pm 6^{\mathrm{b}}$ & $293 \pm 1^{\mathrm{d}}$ & - & - & $34 \pm 2^{\mathrm{b}}$ \\
\hline
\end{tabular}



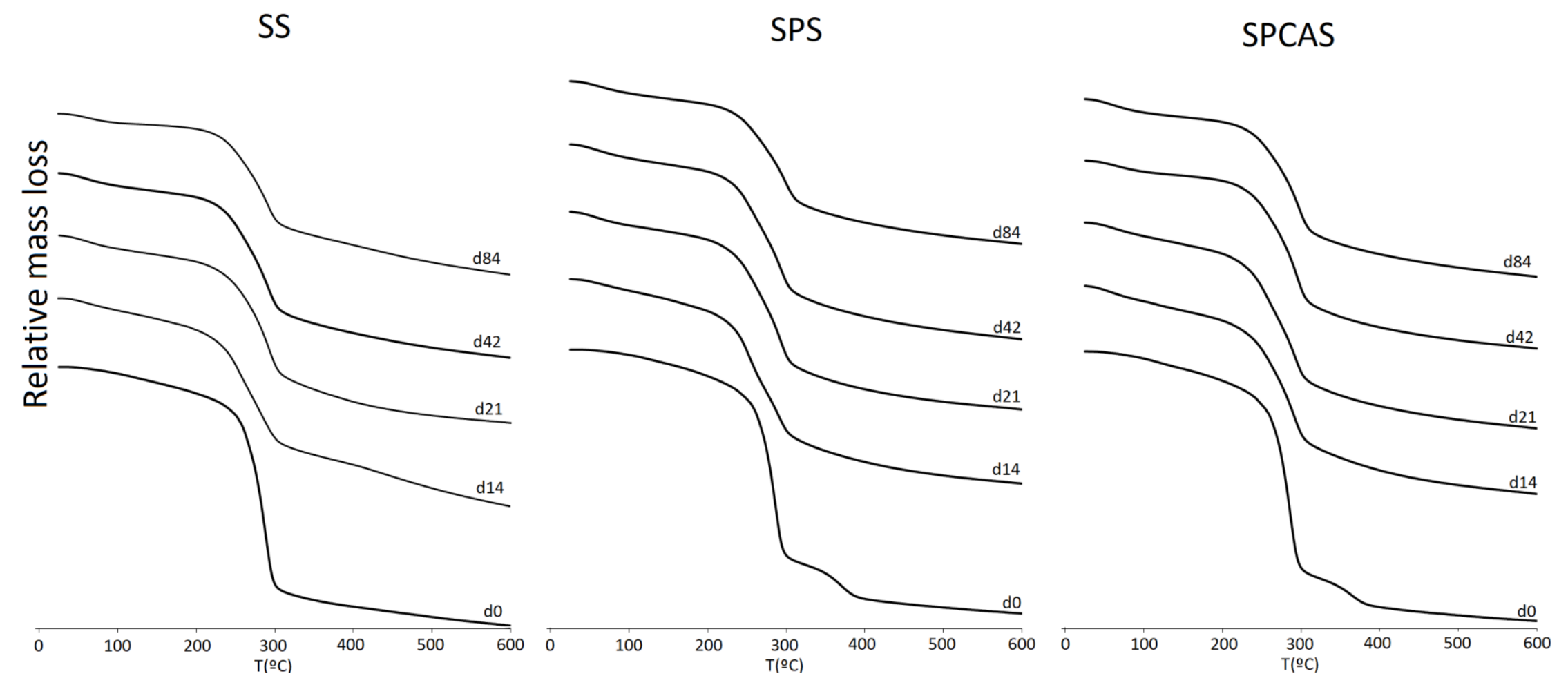

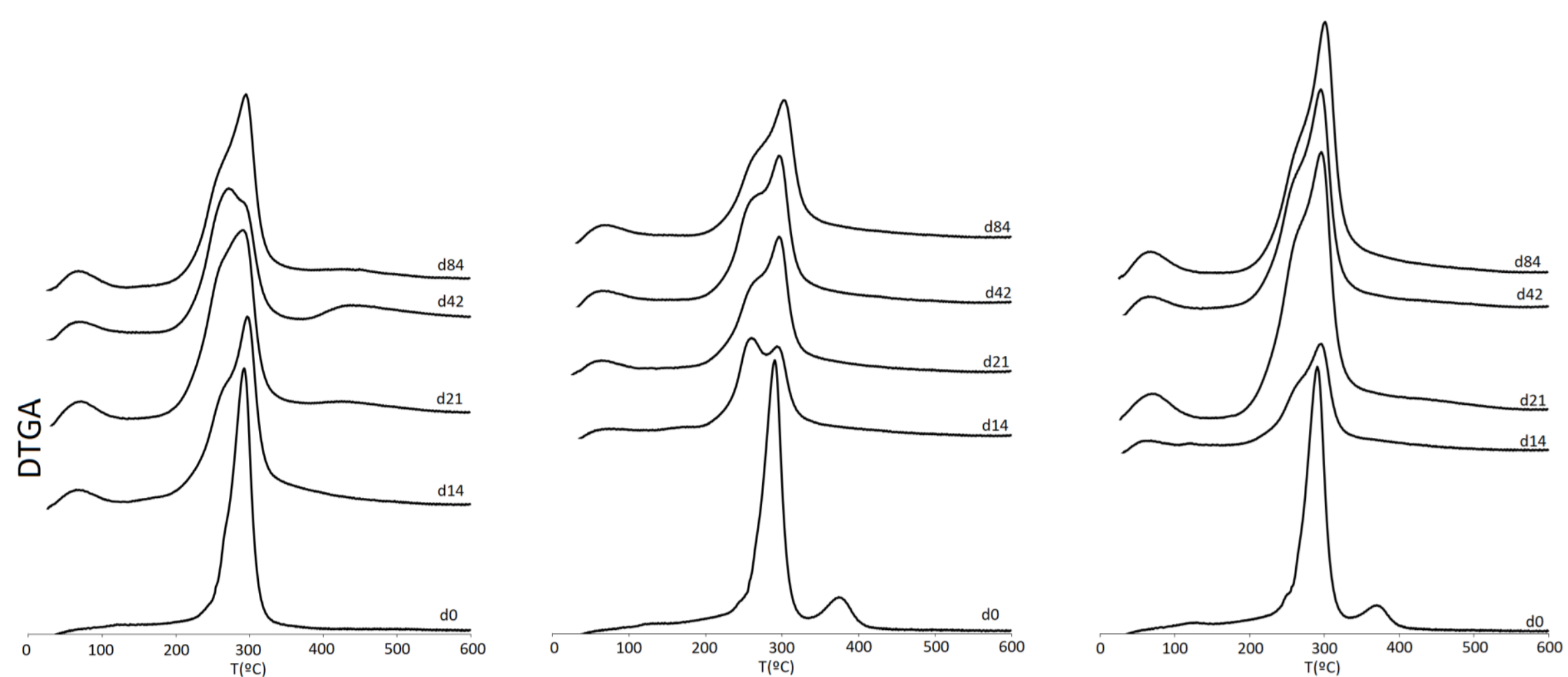

317 Figure 3. TGA and DGTA curves of starch multilayer films submitted to the disintegration process at different composting times $(0,14,21,42$ 318 and 84 days). 


\section{3.4. Biodegradation test}

320 The samples' biodegradability potential was assessed in a laboratory setup by direct measurement 321 of the $\mathrm{CO}_{2}$ generated during aerobic composting at $58 \pm 2 \stackrel{\circ}{\circ}$ for 45 days. The compostable material 322 is used by microorganisms as an energy source for their metabolic activities and cellular growth, which 323 under aerobic conditions means the transformation of the samples' carbon into $\mathrm{CO}_{2}$. The maximum 324 amount of $\mathrm{CO}_{2}$ that could be generated from the samples was theoretically calculated based on the 325 carbon content (Table 1) previously determined through elemental analysis.

326 Figure 4 presents the biodegradation kinetics of the starch based multilayers and the microcrystalline cellulose used as reference material. All samples exhibited the typical sigmoid profile of the respirometric test in agreement with other studies [27], [28]. An initial lag period lasting among 4-18 days, depending on the sample, was observed. This period length is affected by the adaptation/selection time of microorganisms and the time where the degree of material degradation reached about $10 \%$ of the maximum. The presence of carvacrol in SPCAS sample and the higher adhesion forces of starch sheets in SS sample (that increased the effective sample thickness) seemed to delay the start of the biodegradation phase (time from the lag period to the $90 \%$ of maximum biodegradation). A plateau was reached in all samples, after around 30 days, which represents the maximum degradation values reached for each sample. The initial lag period for MCC sample was similar to those found by others authors [28]. For the multilayers, this period was longer than those found in the literature for cast starch based films [28]. This could be due to the different film thickness and polymer structure or crystalline content, affected by the film's processing method. SPS displayed a shorter initial lag period than SS films, probably because of the lack of adherence among hydrophilic (SS) and hydrophobic (PCL) layers [37] in the moist environment, where starch layers swelled promoting the multilayer detachment throughout the process. This enhances the specific film surface area and biodegradation rate. The effect of specific surface area on the biodegradation behaviour of films has also been previously reported by other authors [38].

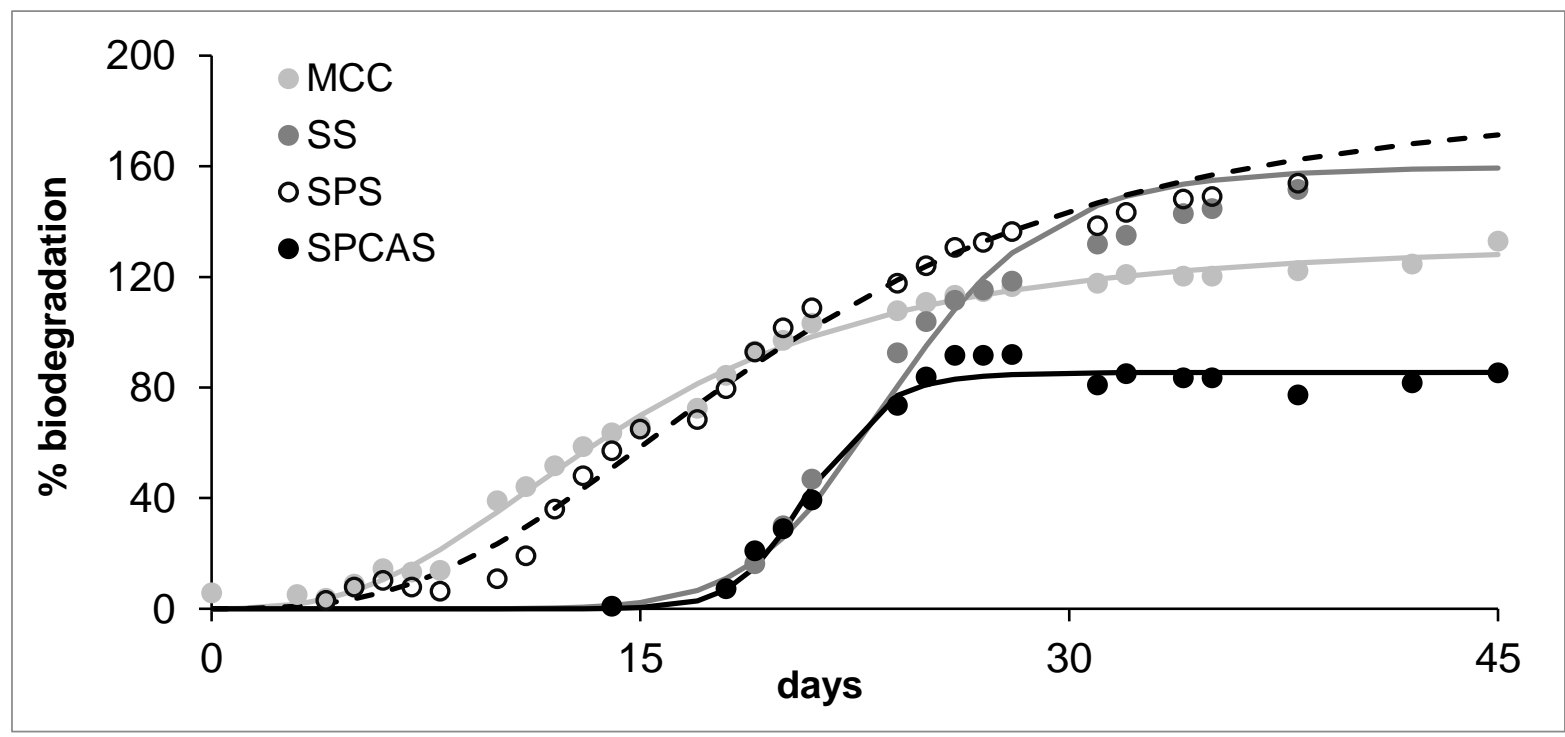


Figure 4. Biodegradation kinetics of MCC and the different films with and without carvacrol throughout the composting time. Experimental data (symbols) and Hill's fitted model (lines).

For starch and cellulose, amylases and cellulases are responsible for the cleavage of glycosidic bonds [39]. The degradation of PCL mainly takes place by enzymatic hydrolytic ester cleavage, which is attributed to microorganisms that secrete extracellular PCL depolymerases such as esterase, cutinase and lipase [40], [41], [42]. The PCL also undergoes hydrolytic degradation due to the presence of hydrolytically labile aliphatic ester linkages, but this degradation is rather slow because of the hydrophobic nature of PCL [43]. After 25 days, biodegradation of the reference sample (MCC) was greater than $70 \%$, thus meeting the requirements established by the ISO 14855 standard [31], and the CA-free film samples reached values of around $100 \%$ of biodegradation $\left(B_{25} \%\right.$ values, Table 4). The biodegradation experimental values were fitted by the Hill's model, and the obtained parameters are shown in Table 4. As can be observed, MCC, SS and SPS films reached maximum biodegradation values greater than $100 \%$ (curve plateau), which can be due to the priming effect. This effect occurs when the compost inoculum in the samples' reactors produces more $\mathrm{CO}_{2}$ than the one in the blank reactors [44], as microflora is overstimulated by small molecules being released into the medium as consequence of the polymer degradation. This effect was not observed in samples containing carvacrol. In fact, SPCAS was not fully degraded during the composting period, reaching effect could limit the growth of the microbial community and its biodegradation action on the films (longer lag period and lower maximum degradation). In fact, the CA loaded electrospun PCL fibres in multilayer films have been reported to exert an effective antimicrobial action due to the CA diffusion into the starch layers [14]. So, the partial migration of the carvacrol to the starch layers in the multiplayer assembly will affect biodegradation of both PCL and S sheets, thus reaching lower final biodegradation values. Other studies carried out with starch and gluten films incorporating active essential oils showed that the presence of these antimicrobials did not significantly inhibit the biodegradation process of the films [27], [28]. In these cases, the use of hydrophilic films, which absorb water easily, contributed to the plasticization of the polymer matrix and thus, to the fast antimicrobial compound release and volatilization, and so, it doesn't affect the microbial assimilation of the films under composting exposure. In contrast, the presence of carvacrol in the multilayer assembly with greater thickness seems to increase the persistence of the antimicrobial in the films, thus partially inhibiting the microbial action and the enzyme access to the polymer, further limiting the biodegradation processes.

Table 4. Hill's parameters: $\mathbf{n}, \mathbf{k}$ (the time needed for $50 \%$ of $B_{\max }$ to occur), $\mathbf{B}_{\max }$ (percentage of biodegradation at infinite time), $B_{25}$ (percentage of biodegradation after 25 days) maximum biodegradation rate $\left(\boldsymbol{\tau}_{\max }\right)$, time at this maximum $\left(\mathbf{t}_{\boldsymbol{\tau} \text { max }}\right)$ for the different films and microcrystalline cellulose (MCC, reference) and $\mathbf{R}^{2}$ (correlation coefficient for the fitted model). 


\begin{tabular}{|l|c|c|c|c|c|c|c|}
\hline \multicolumn{1}{|c|}{ Sample } & $\mathrm{n}$ & $\begin{array}{c}\mathrm{k} \\
\text { (days) }\end{array}$ & $\begin{array}{c}\mathrm{B}_{\max } \\
(\%)\end{array}$ & $\mathrm{B}_{25}(\%)$ & $\begin{array}{c}\tau_{\max } \\
(\% \mathrm{~B} / \mathrm{day})\end{array}$ & $\begin{array}{c}\mathrm{t}_{\mathrm{max}} \\
(\text { days })\end{array}$ & $\mathrm{R}^{2}$ \\
\hline MCC & 2.8 & 14.5 & 134 & 110 & 7.3 & 11 & 0.90 \\
\hline SS & 9.1 & 24.0 & 160 & 95 & 15.2 & 24 & 0.85 \\
\hline SPS & 2.8 & 19.8 & 188 & 124 & 7.6 & 15 & 0.96 \\
\hline SPCAS & 16.2 & 20.9 & 85 & 81 & 16.5 & 21 & 0.80 \\
\hline
\end{tabular}

Figure 5 shows the biodegradation rates obtained from the first derivative of Hill's equation as a function of time for each sample. In Table 4, the maximum biodegradation rate ( $\left.\tau_{\max }\right)$ and the time needed to reach this maximum ( $\left.t_{\tau} \max \right)$ value are shown. SS bilayer exhibited greater degradation rates than SPS (around 15.2 and $7.6 \% \mathrm{~B} /$ day, respectively) but delayed in time. This can be attributed to the greatest adhesion force between the two starch layers in the SS assembly that limit the water diffusion between layers, making the greater sample thickness more effective than in the SPS assembly. In the latter, the starch swelling in the wet ambient should enhance the detachment of the layers, reducing the effective thickness of the multilayer. This should favour a more extended biodegradation process with lower maximum biodegradation rate, in line with the progressive increase in the specific surface area of the multilayer assembly. Additionally, the polyester enzymatic degradation (leading to small organic acid fractions) could also affect the biochemical route of starch degradation. SPS films with and without carvacrol exhibited different maximum biodegradation rates (16.5 and $7.6 \% \mathrm{~B} /$ day, respectively) and these values were reached at different incubation times (21 and 15 days for SPCAS and SPS, respectively). So, those films incorporating CA needed a longer composting exposure time to reach the maximum biodegradation rate than those films without the antimicrobial agent. This could be attributed to the time necessary for carvacrol volatilization and the subsequent reduction of its inhibitory effect.

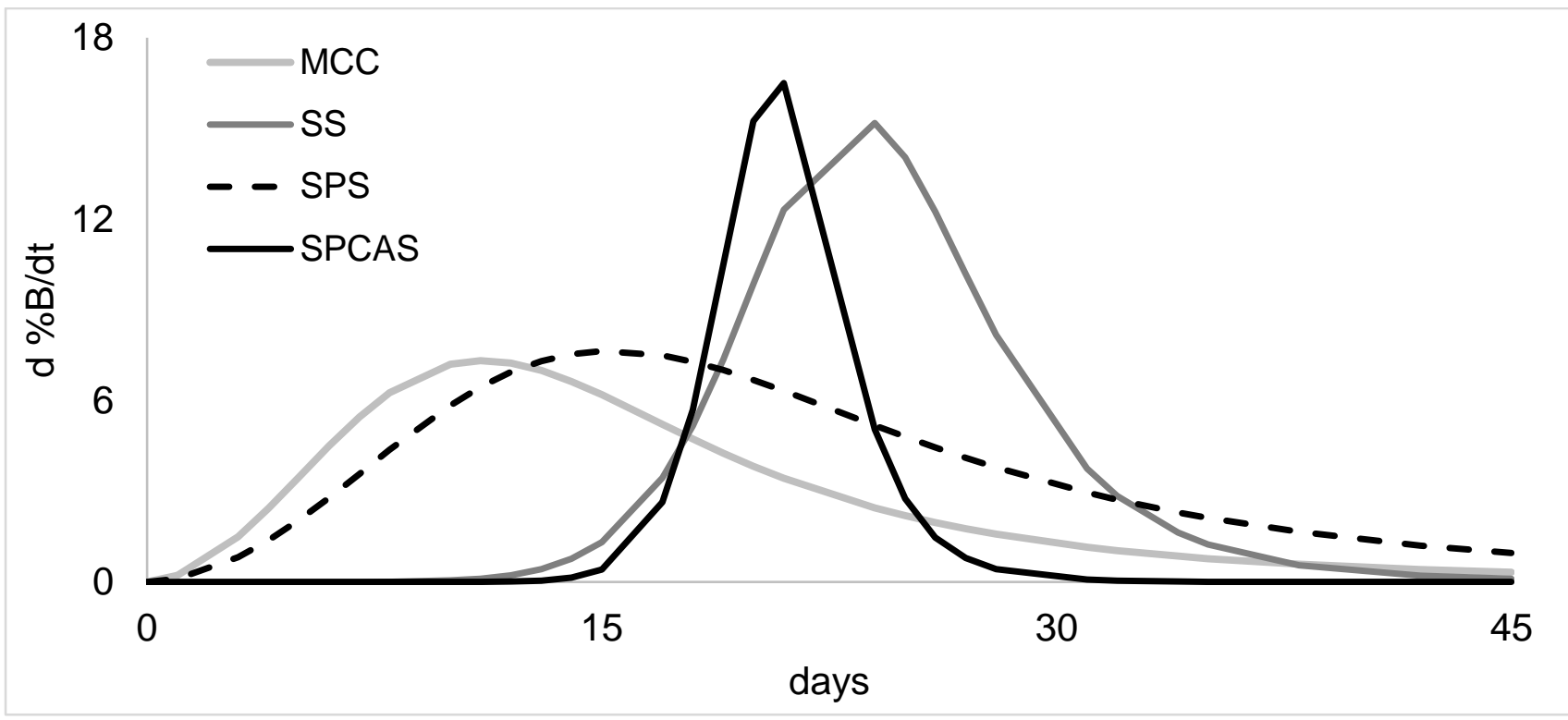


400 Figure 5. Biodegradation rates of MCC and the different films with and without carvacrol throughout 401 the composting time.

\section{Conclusion}

All multilayer films (containing or not CA) exhibited the same trend of disintegration throughout the composting exposure time. The biodegradation process of pure bilayer starch films was retarded, in comparison with starch-PCL multilayer, by the greater effective thickness of the bilayer, due to the highest adhesion forces between the starch sheets. In contrast, starch-PCL multilayers, exhibited an earlier, more extended degradation behaviour with lower peak rate. The biodegradation test revealed that the presence of CA notably affected the compost inoculum activity, thus limiting the biodegradability of the CA-loaded multilayers to a maximum value of around $85 \%$. Nevertheless, the biodegradation values reached by the CA loaded films were very close to that established by the standard ISO method to be considered as biodegradable material (90\%). Further biodegradation studies under longer composting times are recommended to evaluate the total biodegradation of carvacrol-loaded SPS films.

\section{References}

422 [1]. R. C. Thompson, C. J. Moore, F. S. vom Saal, S. H. Swan. Plastics, the environment and human health: current consensus and future trends 364. Phil. Trans. R. Soc. B 364 (2009) 1526. http://doi.org/10.1098/rstb.2009.0053

425 [2]. www.epa.gov (page accessed in May 2019)

426 [3]. http://www.epro-plasticsrecycling.org (page accessed in May 2019).

427 [4]. S. Jahan, V. Strezov, H. Weldekidan, R. Kumar, T. Kan, S.A. Sarkodie, J. He, B. Dastjerdi, S.P. 428 Wilson, Interrelationship of microplastic pollution in sediments and oysters in a seaport environment 429 of the eastern coast of Australia, Sci. Total Environ. 695 (2019) 133924. 430 doi:10.1016/j.scitotenv.2019.133924.

431 [5]. J. Li, X. Qu, L. Su, W. Zhang, D. Yang, P. Kolandhasamy, D. Li, H. Shi, Microplastics in mussels 432 along the coastal waters of China, Environ. Pollut. 214 (2016) 177-184. 433 doi:10.1016/j.envpol.2016.04.012.

434 [6]. M. Renzi, C. Guerranti, A. Blašković, Microplastic contents from maricultured and natural mussels, 435 Mar. Pollut. Bull. 131 (2018) 248-251. doi:10.1016/j.marpolbul.2018.04.035. 
436 [7]. M.F.M. Santana, L.G. Ascer, M.R. Custódio, F.T. Moreira, A. Turra, Microplastic contamination in 437 natural mussel beds from a Brazilian urbanized coastal region: Rapid evaluation through 438 bioassessment, Mar. Pollut. Bull. 106 (2016) 183-189. doi:10.1016/j.marpolbul.2016.02.074.

439 [8]. A.J.R. Watts, M.A. Urbina, S. Corr, C. Lewis, T.S. Galloway, Ingestion of Plastic Microfibers by 440 the Crab Carcinus maenas and Its Effect on Food Consumption and Energy Balance, Environ. Sci. 441 Technol. 49 (2015) 14597-14604. doi:10.1021/acs.est.5b04026.

442 [9]. Jinhui, X. Sudong, N. Yan, P. Xia, Q. Jiahao, X. Yongjian, Effects of microplastics and attached 443 heavy metals on growth, immunity, and heavy metal accumulation in the yellow seahorse, 444 Hippocampus kuda Bleeker, Mar. Pollut. Bull. $149 \quad$ (2019) 110510. 445 doi:10.1016/j.marpolbul.2019.110510.

446 [10]. R. Qiao, Y. Deng, S. Zhang, M.B. Wolosker, Q. Zhu, H. Ren, Y. Zhang, Accumulation of different 447 shapes of microplastics initiates intestinal injury and gut microbiota dysbiosis in the gut of zebrafish, 448 Chemosphere. 236 (2019) 124334. doi:10.1016/j.chemosphere.2019.07.065.

449 [11]. EFSA CONTAM Panel (EFSA Panel on Contaminants in the Food Chain) Statement on the 450 presence of microplastics and nanoplastics in food, with particular focus on seafood EFSA J., 14 (6) 451 (2016), pp. 4501-4531

452 [12]. A. Heimowska, M. Morawska, A. Bocho-Janiszewska, Biodegradation of poly( $\varepsilon$-caprolactone) in 453 natural water environments, Polish J. Chem. Technol. 19 (2017) 120-126. doi:10.1515/pjct-20174540017.

455 [13]. R. Ortega-Toro, J. Contreras, P. Talens, A. Chiralt., Physical and structural properties and 456 thermal behaviour of starch-poly( $\varepsilon$-caprolactone) blend films for food packaging, Food Packag. Shelf 457 Life. 5 (2015) 10-20. doi:10.1016/j.fpsl.2015.04.001.

458 [14]. A. Tampau, C. González-Martínez, A. Chiralt, Release kinetics and antimicrobial properties of 459 carvacrol encapsulated in electrospun poly-( $\varepsilon$-caprolactone) nanofibres. Application in starch 460 multilayer films, Food Hydrocoll. 79 (2018) 158-169. doi:10.1016/j.foodhyd.2017.12.021.

461 [15]. A. Tampau, C. González-Martinez, A. Chiralt, Carvacrol encapsulation in starch or PCL based 462 matrices by electrospinning, J. Food Eng. 214 (2017) 245-256. doi:10.1016/j.jfoodeng.2017.07.005. 463 [16]. M. Ramos, A. Jiménez, M. Peltzer, M.C. Garrigós, Characterization and antimicrobial activity 464 studies of polypropylene films with carvacrol and thymol for active packaging, J. Food Eng. 109 (2012) 465 513-519. doi:10.1016/j.jfoodeng.2011.10.031.

466 [17]. A. Ben Arfa, L. Preziosi-Belloy, P. Chalier, N. Gontard, Antimicrobial paper based on a soy 467 protein isolate or modified starch coating including carvacrol and cinnamaldehyde, J. Agric. Food 468 Chem. 55 (2007) 2155-2162. doi:10.1021/jf0626009.

469 [18]. A. Ultee, M.H.J. Bennik, R. Moezelaar, The phenolic hydroxyl group of carvacrol is essential for 470 action against the food-borne pathogen Bacillus cereus, Appl. Environ. Microbiol. 68 (2002) 1561471 1568. doi:10.1128/AEM.68.4.1561-1568.2002. 
472 [19]. S. Tunc, E. Chollet, P. Chalier, L. Preziosi-Belloy, N. Gontard, Combined effect of volatile 473 antimicrobial agents on the growth of Penicillium notatum, Int. J. Food Microbiol. 113 (2007) 263-270. 474 doi:10.1016/j.jijoodmicro.2006.07.004.

475 [20]. B. Tepe, M. Sokmen, H.A. Akpulat, D. Daferera, M. Polissiou, A. Sokmen, Antioxidative activity 476 of the essential oils of Thymus sipyleus subsp. sipyleus var. sipyleus and Thymus sipyleus subsp. sipyleus var. rosulans, J. Food Eng. 66 (2005) 447-454. doi:10.1016/j.jfoodeng.2004.04.015. [21]. S. Gursul, I. Karabulut, G. Durmaz, Antioxidant efficacy of thymol and carvacrol in microencapsulated walnut oil triacylglycerols, Food Chem. 278 (2019) 805-810. doi:10.1016/j.foodchem.2018.11.134.

[22]. Joint FAO/WHO Expert Committee on Food Additives Fifty-seventh meeting Rome, 5-14 June 2001, (2001). [23]. Efsa, Scientific Opinion on the Safety and efficacy of phenol derivates containing ring-alkyl, ringalkoxy and side- chains with an oxygenated functional group (chemical group 25) when used as flavourings for all species, Efsa J. 10 (2012) 2573. doi:10.2903/j.efsa.2012.2573.

[24]. G. Kavoosi, S.M.M. Dadfar, A. Mohammadi Purfard, R. Mehrabi, Antioxidant and antibacterial properties of gelatin films incorporated with carvacrol, J. Food Saf. 33 (2013) 423-432. doi:10.1111/jfs.12071.

[25]. M.A. López-Mata, S. Ruiz-Cruz, N.P. Silva-Beltrán, J.D.J. Ornelas-Paz, P.B. Zamudio-Flores, S.E. Burruel-Ibarra, Physicochemical, antimicrobial and antioxidant properties of chitosan films incorporated with carvacrol, Molecules. 18 (2013) 13735-13753. doi:10.3390/molecules181113735. [26]. L. Higueras, G. López-Carballo, P. Hernández-Muñoz, R. Catalá, R. Gavara, Antimicrobial packaging of chicken fillets based on the release of carvacrol from chitosan/cyclodextrin films, Int. J. Food Microbiol. 188 (2014) 53-59. doi:10.1016/j.jfoodmicro.2014.07.018.

[27]. M.P. Balaguer, J. Villanova, G. Cesar, R. Gavara, P. Hernandez-Munoz, Compostable properties of antimicrobial bioplastics based on cinnamaldehyde cross-linked gliadins, Chem. Eng. J. 262 (2013) 447-455. doi:10.1016/j.cej.2014.09.099.

[28]. A.I. Cano, M. Cháfer, A. Chiralt, C. González-Martínez, Biodegradation behavior of starch-PVA films as affected by the incorporation of different antimicrobials, Polym. Degrad. Stab. 132 (2016) 1120. doi:10.1016/j.polymdegradstab.2016.04.014. [29]. European Union, European Parliament and Council Directive 94/62/EC on Packaging and Packaging Waste, Off. J. Eur. Communities No L 365/10. 1993 (1994) 10-23. doi:10.1038/sj.bdj.4811054. [30]. ISO 20200, Plastics - Determination of the Degree of Disintegration of Plastic Materials under Simulated Composting in a Laboratory-scale Test, 2004.

[31]. UNE-EN ISO 14855-1, Determinación de la biodegradabilidad aeróbica final de materiales plásticos en condiciones de compostaje controladas, in: Método según el análisis de dióxido de carbono generado, 2012. Parte 1: Método general. 
[32]. E. Talón, M. Vargas, A. Chiralt, C. González-Martínez, Eugenol incorporation into thermoprocessed starch films using different encapsulating materials, Food Packag. Shelf Life. 21 (2019) 100326. doi:10.1016/j.fpsl.2019.100326.

[33]. E. Castro-Aguirre, R. Auras, S. Selke, M. Rubino, T. Marsh, Insights on the aerobic biodegradation of polymers by analysis of evolved carbon dioxide in simulated composting conditions, Polym. Degrad. Stab. 137 (2017) 251-271. doi:10.1016/j.polymdegradstab.2017.01.017.

[34]. S. Collazo-Bigliardi, R. Ortega-Toro, A.Chiralt, Reinforcement of thermoplastic starch films with cellulose fibres obtained from rice and coffee husks, J. Renew. Mater. 6 (2018) 599-610. doi:10.32604/JRM.2018.00127.

[35]. P.A. Sreekumar, M.A. Al-Harthi, S.K. De, Studies on compatibility of biodegradable starch/polyvinyl alcohol blends, Polym. Eng. Sci. 52 (2012) 2167-2172. doi:10.1002/pen.23178.

[36]. E. Rudnik, Biodegradability testing of compostable polymer materials, in: Compost. Polym. Mater, Elsevier, 2008: pp. 112-166. doi:10.1016/B978-008045371-2.50008-1.

[37]. R.P. Singh, J.K. Pandey, D. Rutot, P. Degée, P. Dubois, Biodegradation of poly $(\varepsilon-$ caprolactone)/starch blends and composites in composting and culture environments: The effect of compatibilization on the inherent biodegradability of the host polymer, Carbohydr. Res. 338 (2003) 1759-1769. doi:10.1016/S0008-6215(03)00236-2.

[38]. H.S. Yang, J.S. Yoon, M.N. Kim, Dependence of biodegradability of plastics in compost on the shape of specimens, Polym. Degrad. Stab. 87 (2005) 131-135. doi:10.1016/j.polymdegradstab.2004.07.016.

[39]. B.P. Wasserman, Principles of enzymology for the food sciences, 2nd edition. John R. Whitaker, Marcel Dekker, Inc., 270 Madison Ave., New York, NY 10016. 1994. 648 pages. \$185.00, J. Food Saf. 15 (1995) 365a - 366. doi:10.1111/j.1745-4565.1995.tb00147.x.

[40] C.A. Murphy, J.A. Cameron, S.J. Huang, R.T. Vinopal, Fusarium polycaprolactone depolymerase is cutinase, Appl. Environ. Microbiol. 62 (1996) 456-460.

[41] C.A. Murphy, J.A. Cameron, S.J. Huang, R.T. Vinopal, A second polycaprolactone depolymerase from Fusarium, a lipase distinct from cutinase, Appl. Microbiol. Biotechnol. 50 (1998) 692-696. doi:10.1007/s002530051352.

[42] Y. Tokiwa, B.P. Calabia, C.U. Ugwu, S. Aiba, Biodegradability of plastics, Int. J. Mol. Sci. 10 (2009) 3722-3742. doi:10.3390/ijms10093722.

[43] A. Banerjee, K. Chatterjee, G. Madras, Enzymatic degradation of polycaprolactone-gelatin blend, Mater. Res. Express. 2 (2015). doi:10.1088/2053-1591/2/4/045303.

[44] J. Shen, R. Bartha, Priming effect of glucose polymers in soil-based biodegradation tests, Soil Biol. Biochem. 29 (1997) 1195-1198. doi:10.1016/S0038-0717(97)00031-X. 